THIRTY YEARS FOLLOW UP OF THE NAIVE T CELL COMPARTMENT AFTER NEONATAL THYMECTOMY DUE TO CARDIAC SURGERY

\author{
A.W.L. Schadenberg ${ }^{1,2}$, R. van Gent ${ }^{3}$, \\ R.-J.A. Nievelstein ${ }^{4}$, F. Haas ${ }^{5}$, J.A.M. Borghans ${ }^{3}$, \\ N.J.G. Jansen ${ }^{1}$ \\ ${ }^{1}$ Paediatric Intensive Care, ${ }^{2}$ Paediatric \\ Immunology, University Medical Center Utrecht, \\ Wilhelmina Children's Hospital, 3Immunology, \\ University Medical Center Utrecht, ${ }^{4}$ Paediatric \\ Radiology, ${ }^{5}$ Paediatric Cardiothoracic Surgery, \\ University Medical Center Utrecht, Wilhelmina \\ Children's Hospital, Utrecht, The Netherlands
}

Background and aims: Surgical correction of congenital heart defects at neonatal age frequently involves total thymectomy. Initial reports suggest that neonatal thymectomy could have serious consequences, both short and long term, for the composition of the $\mathrm{T}$ cell compartment. Especially the naive $T$ cell compartment would be at risk of accelerated immunosenescence. This study investigated the maintenance of the naive $T$ cell compartment in the first three decades after neonatal thymectomy due to cardiac surgery.

Methods: Thirty-nine patients were investigated after total neonatal thymectomy due to cardiac surgery. Naive and memory CD4+ and CD8+ T cell compartments were evaluated by flow cytometry, thymic output determined by TREC content and peripheral proliferation by Ki67. All data were compared to healthy controls. Presence of thymic tissue after earlier thymectomy was determined during re-operation or MRI.

Results: Peripheral proliferation could not keep up with loss of thymic output in the first 10 years following thymectomy resulting in low naive $\mathrm{T}$ cell numbers. However, after 10 years renewed presence and activity of thymus replenished the naive $\mathrm{T}$ cell compartment to normal numbers for age.

Conclusions: Neonatal thymectomy clearly shows reduction in naive $T$ cell numbers in the first 10 years of life, followed by reoccurrence of thymus and subsequently re-establishment of normal naive $T$ cell numbers in the majority of patients. As not all patients showed evidence of re-growth of functional thymus it remains prudent to save as much thymic tissue as possible during neonatal cardiac surgery.

\section{MILRINONE IS PREFERRED TO LEVOSIMENDAN FOR MESENTERIC PERFUSION IN HYPOXIA-REOXYGENATED NEWBORN PIGLETS ON DOPAMINE}

N. Manouchehri ${ }^{1}$, D. Bigam ${ }^{1}$, T. Churchill ${ }^{1}$, C. Joynt ${ }^{2}$, M. Vento ${ }^{3}$, P.-Y. Cheung ${ }^{1,2,4}$

${ }^{1}$ Surgery, ${ }^{2}$ Pediatrics, University of Alberta, Edmonton, AB, Canada, ${ }^{3}$ Neonatology, University of Valencia, Valencia, Spain, ${ }^{4}$ Pharmacology, University of Alberta, Edmonton, AB, Canada

Objectives: To determine the effect on systemic and regional perfusion of adding milrinone or levosimendan to a background infusion of dopamine in newborn piglets following hypoxia-reoxygenation $(\mathrm{H}-\mathrm{R})$.

Methods: Piglets (1-4d) were instrumented for continuous monitoring of systemic and pulmonary arterial pressures, cardiac output $(\mathrm{Cl})$ and common carotid, superior mesenteric and renal arterial flows. Sham piglets $(n=6)$ had no H-R. H-R piglets underwent $2 \mathrm{~h}$ of hypoxia followed by reoxygenation with $100 \%(0.5 \mathrm{~h})$ and $21 \%$ oxygen (3.5h). H-R piglets were blindly randomized ( $n=6 /$ group) to saline control or dopamine $(10 \mathrm{mcg} / \mathrm{kg} / \mathrm{min})$ with milrinone $(D+M-50 \mathrm{mcg} / \mathrm{kg}$ bolus then $0.5 \mathrm{mcg} /$ $\mathrm{kg} / \mathrm{min}$ ) or levosimendan (D+L - $24 \mathrm{mcg} / \mathrm{kg}$ bolus then $0.2 \mathrm{mcg} / \mathrm{kg} / \mathrm{min}$ ). Tissue was collected for biochemical and histological analysis. Data were analyzed using ANOVA.

Results: Following $2 \mathrm{~h}$ of hypoxia, H-R piglets were in cardiogenic shock with depressed $\mathrm{Cl}$ and hypotension. $D+M$ and $D+L$ treatments increased heart rate, $\mathrm{Cl}$ and systemic oxygen delivery (all $p<0.05$ vs. controls) without significant effects on pressures. Both treatments improved common carotid flow, oxygen delivery and vascular resistance ( $p<0.05$ vs. controls). D+M additionally improved superior mesenteric flow and oxygen delivery ( $p<0.05$ vs. controls). No disparate effect was appreciated on renal perfusion. $\mathrm{D}+\mathrm{M}$ piglets had lower myocardial oxidized-to-total glutathione ratio than controls $(p=0.05)$. No differences were appreciated in plasma lactate, myocardial lactate or histologic indices of H-R injury.

Conclusions: In H-R newborn piglets, either milrinone or levosimendan addition to dopamine similarly improves systemic hemodynamics. Milrinone addition, in particular, improves mesenteric perfusion and attenuates myocardial oxidative stress. 